research. Neither the reputations of orthopaedic surgeons nor the interests of their patients are served by acquiescence in strongly held opinions which are unsupported by scientific evidence.

I. G. CHALMERS R. E. COLLINS K. DICKERSIN

\section{REFERENCES}

Campling EA, Devlin HB, Hoile RW, Lunn JN. The report of the national confidential enquiry into perioperative deaths 1990. London: NCEPOD, 1992.
Chalmers I. Improving the quality and dissemination of reviews of clinical research. In: Lock SP, ed. The future of medical journals. London: British Medical Journal, $1991: 127-46$.

Collins R, Doll R, Peto R. Ethics of clinical trials. In: Williams CJ, ed. Introducing new treatments for cancer: practical, ethical and legal problems. Chichester: John Wiley, 1992:49-65.

Collins R, Scrimgeour A, Yusuf S, Peto R. Reduction in fatal pulmonary embolism and venous thrombosis by perioperative administration of subcutaneous heparin. New Engl J Med 1988; 318:1162-73.

Dickersin K. Why register clinical trials? - revisited. Controlled Clin Trials 1992 :in press.

Rudicel S, Esdaile J. The randomized clinical trial in orthopaedics: obligation or option? J Bone Joint Surg [Am] 1985; 67-A:1 284-93.

Turner JA, Ersek M, Herron L, Deyo R. Surgery for lumbar spinal stenosis: attempted meta-analysis of the literature. Spine 1992; $17: 1-8$

\title{
Screening for congenital dislocation of the hip
}

It is now many years since the work of Ortolani (1937), von Rosen $(1956,1962)$ and Barlow (1962) ushered in the era of screening for congenital dislocation of the hip $(\mathrm{CDH})$. It seemed at first that the problem of the late diagnosed established dislocation had been solved but, as more and more centres published their results, doubts began to emerge. Although the number varied, all reported some cases which had been missed by the screening programme.

Why were the early expectations not fulfilled? In retrospect it seems obvious that some of the criteria that we would now demand of a screening programme had not been met. These would include an accurate and repeatable test, an understanding of the natural history of the condition, and a safe and dependable method of treatment. The programme should also make economic sense. How does screening for CDH measure up? Any conclusions must be population-based, and it is significant that the poorest results have been reported by those who have studied a population rather than the captive occupants of a maternity hospital (McKenzie 1972; Williamson 1972; Jones 1977; Bjerkreim and Arseth 1978; Catford, Bennet and Wilkinson 1982).

Before the introduction of screening, the presumed incidence of established dislocation was 0.65 per 1000 . It has probably risen since (Klingberg et al 1976; Catford et al 1982) and a generally accepted figure now would be around 1.5 per 1000 . Yet, by clinical testing, 10 to 20 neonates per 1000 are considered to have abnormal hips. Clearly, we are overtreating this disorder.

When screening was introduced the natural history of the condition was ill understood. It was, for example,

G. C. Bennet, FRCS Ed, Consultant Orthopaedic Surgeon Royal Hospital for Sick Children, Yorkhill, Glasgow G3 8SJ, Scotland. (C) 1992 British Editorial Society of Bone and Joint Surgery $0301-620 X / 92 / 5473 \$ 2.00$

J Bone Joint Surg [Br] 1992; 74-B :643-4 assumed that dislocation arose by progression from an unstable hip but this is no longer certain (Berman and Klenerman 1986). Ultrasound studies have allowed the structure of the neonatal joint to be assessed better; it is now appreciated that a hip with normal anatomy can be unstable, and that one with very abnormal morphology can, nevertheless, prove to be stable (Clarke 1986; Tonnis, Storch and Ulbrich 1990). This recognition of our ignorance of the significance of the hip dysplasias must lead to a reappraisal of our expectations of clinical screening.

There is no point in screening unless a safe and effective treatment is available, one that will alter the natural history of the disease for the better. Overtreatment would not matter if it were risk-free but unfortunately it is not, and some cases of avascular necrosis have occurred in every series (Elsworth and Walker 1986; Bradley, Weatherill and Benson 1987).

Ultrasonic examination has the advantage over clinical testing in that it allows objective documentation of the anatomy of the developing hip in the neonatal period, and it is safe and non-invasive. It is particularly useful in selecting out those unstable hips that require treatment from those that do not (Gardiner and Dunn 1990) and in assessing their response to splintage. Its place in primary screening, however, has yet to be established. Skilled operators are required and the method has a low specificity in the first week of life, so that its use has been associated with high follow-up and intervention rates. It can be used selectively, for children considered to be at high risk, but children without risk factors may still present late (Clarke, Clegg and AlChalabi 1989).

Radiographs are of little value in the first few weeks of life and only begin to provide useful information at about three months of age, by which time adaptive changes have occurred. Although radiography may be useful as a safety net to diagnose those cases that have 
been missed by the primary screening process, there are valid economic and safety arguments against its more routine use.

There are three papers in this issue of the Journal all of which address these problems in different ways. Krikler and Dwyer (p. 701) describe what might be regarded as the traditional course and advocate better organised and more efficient screening. They report fewer missed cases in a hospital where the screening was more closely supervised than at another comparable unit with less formal arrangements. There was, however, no significant difference between the two in the number of children who eventually required surgical treatment. Failure to alter the natural history of the condition must be regarded as a failure of the screening process, and must call into question its economic benefits (Fulton and Barer 1984).

Poul et al (p. 695) also advocate careful screening performed by orthopaedic surgeons, but they subjected all the children to radiography at three months. Among those who had been adjudged clinically normal, 0.6 per 1000 were found to have dislocation or subluxation of the hip and a further nine per 1000 had acetabular dysplasia. The significance of the latter condition is unclear as not all have a bad prognosis.

Garvey et al (p. 704) take the pragmatic view that, even with the best testing, some cases will be missed. They selected those children most at risk of developing dislocation and screened them more intensively: all this group had radiographic examinations at four months. The predictive factor found to be of most significance was a positive family history; of these children, $18 \%$ were found to have previously unsuspected anatomical abnormalities.

Clinical screening for CDH is well established. Its effect is to minimise but not to prevent the late diagnosis of congenital dislocation of the hip.

When an abnormality is detected by clinical tests, ultrasonic examination may allow more accurate assessment and help to decide whether treatment is required. Concentrating on those at special risk, and routinely examining them by radiography or ultrasound, will further reduce the number of late diagnosed cases. But in spite of our best efforts, the late diagnosed dislocated hip is likely to be with us for some time yet.

GEORGE C. BENNET

\section{REFERENCES}

Barlow TG. Early diagnosis and treatment of congenital dislocation of the hip. J Bone Joint Surg [ Br] 1962; 44-B:292-301.

Berman L, Klenerman L. Ultrasound screening for hip abnormalities: preliminary findings in 1001 neonates. $\mathrm{Br} \mathrm{Med} J \mathrm{~J}$ 1986; 293:719-22.

Bjerkreim I, Arseth PH. Congenital dislocation of the hip in Norway: late diagnosis CDH in the years 1970-4. Acta Paediatr Scand 1978; 67:329-32.

Bradley J, Weatherill M, Benson MKD. Splintage for congenital dislocation of the hip: is it safe and reliable? J Bone Joint Surg [Br] 1987; 69-B :257-63.

Catford JC, Bennet GC, Wilkinson JA. Congenital hip dislocation : an increasing and still uncontrolled disability? Br Med J 1982; 285:1527-30.

Clarke NM. Sonographic clarification of the problems of neonatal hip instability. J Pediatr Orthop 1986; 6:527-32.

Clarke NMP, Clegg J, Al-Chalabi AN. Ultrasound screening of hips at risk for $\mathrm{CDH}$ : failure to reduce the incidence of late cases. $J$ Bone Joint Surg [Br] 1989; 71-B:9-12.

Elsworth C, Walker G. The safety of the Denis Browne abduction harness in congenital dislocation of the hip. J Bone Joint Surg [Br] 1986; 86-B:275-7.

Fulton MJ, Barer ML. Screening for congenital dislocation of the hip: an economic appraisal. Can Med Assoc J 1984; 130:1149-56.

Gardiner HM, Dunn PM. Controlled trial of immediate splinting versus ultrasonographic surveillance in congenitally dislocatable hips. Lancet 1990; 336:1553-6.

Jones D. An assessment of the value of examination of the hip in the newborn. J Bone Joint Surg [Br] 1977; 59-B:318-22.

Klingberg MA, Chen R, Chemke J, Levin S. Rising rates of congenital dislocation of the hip (letter). Lancet 1976; 1:298.

McKenzie IG. Congenital dislocation of the hip: the development of a regional service. J Bone Joint Surg [Br] 1972; 51-B:18-39.

Ortolani M. Un segno poco noto e sua importanza per la diagnosi precoce di prelussazione congenita dell'anca. Pediatria 1937; 45:129.

Tonnis D, Storch K, Ulbrich H. Results of newborn screening with and without sonography and correlation of risk factors. $J$ Pediatr Orthop 1990; 10:145-52.

von Rosen S. Early diagnosis and treatment of congenital dislocation of the hip joint. Acta Orthopaedica Scandinavica 1956; 26:136.

von Rosen S. Diagnosis and treatment of congenital dislocation of the hip in the new-born. J Bone Joint Surg [Br] 1962; 44-B:284-91.

Williamson J. Difficulties of early diagnosis and treatment of congenital dislocation of the hip in Northern Ireland. J Bone Joint Surg [ Br] 1972; 54-B:13-17. 